Inteligência Artificial e a Lei de Direitos Autorais

\title{
Artificial Intelligence and the Copyright Law
}

Jefferson David Asevedo Ramos ${ }^{1}$, Leandro Gomes da Silva², David Nadler Prata ${ }^{3}$

\section{RESUMO}

Os Sistemas de Inteligência Artificial ao atuarem de forma autônoma, quer dizer, sem a influência humana, alteraram a forma como passamos a ver o processo criativo. Em que pese esta insofismável realidade, a legislação de direitos autorais não reconhece o poder criativo destes Sistemas, tanto que as obras originadas por não humanos acabam por cair no domínio público. O presente artigo aborda a necessidade de revisão da legislação autoral, defendendo a necessidade de ser considerado como autor de uma obra produzida por Sistemas de Inteligência Artificial o desenvolvedor do sistema ou o contratante do serviço. Esta necessária revisão da norma não apenas incentivaria o uso da Inteligência Artificial, como permitiria, sem longa alteração normativa, o progresso da ciência.

Palavras-chave: Inteligência Artificial. Legislação Autoral. Revisão.

\section{ABSTRACT}

When Artificial Intelligence Systems started to act as autonomous agents, that means, without human influence, they altered the way we see the creative process. Despite this unquestionable reality, copyright does not recognize the creative capacity of these systems, so, the works originated by non-humans eventually fall into the public domain. This article discusses the copyright law, understanding that the author of a work produced by Artificial Intelligence Systems is either from the system developer or from the contracting party. This law review is necessary not only to encourage the use of Artificial Intelligence, but would allow the progress of science without long normative change.

Keywords: Artificial Intelligence. Copyright. Review.

${ }^{1}$ Mestrando, Programa de Pós Graduação em Modelagem

Computacional de Sistemas-UFT.

E-mail:

ramos_jefferson@hotmail.com

${ }^{2}$ Mestrando, Programa de Pós Graduação em Modelagem Computacional de Sistemas-UFT.

${ }^{3}$ Doutor, Programa de Pós Graduação em Modelagem Computacional de Sistemas-UFT. 


\section{INTRODUÇĀOO}

Inovar, esta é a peça que move nossa sociedade para o futuro, sendo tão relevante para o desenvolvimento de uma nação que nossa Carta Constitucional resolveu a ela se referir de forma expressa em seu Capítulo IV, dentro da chamada Ordem Social.

Com o aumento do uso da Inteligência Artificial mais e mais trabalhos são frutos do trabalho de autores não-humanos. Algoritmos complexos e softwares de aprendizado nos tornaram conscientes do fato de "não sermos mais as únicas fontes criativas" (THALER, 2013) $)^{1}$.

Apesar desta realidade, a legislação de Direitos Autorais no Brasil ainda não foi capaz de reconhecer o avanço tecnológico que estamos hoje vivenciando, frente a ausência de proteção legal para as obras desenvolvidas autonomamente por meio dos Sistema de Inteligência Artificial.

O presente artigo trata das obras geradas por meio dos Sistemas de Inteligência Artificial e da ausência de proteção legal, um vácuo normativo causador de grave dano não apenas aos desenvolvedores de programas de inteligência artificial, mas como a toda a sociedade.

Discute o artigo a necessidade de a legislação brasileira autoral, tal como faz a legislação do Reino Unido, reconhecer como autor de um trabalho gerado autonomamente por um Sistema de Inteligência Artificial o contratante do serviço ou o desenvolvedor do programa, solução simples, mas eficaz para impedir que as obras geradas por estes Sistemas caiam em domínio público.

Foi utilizada como estratégia metodológica a revisão bibliográfica, em especial da legislação brasileira e de trabalhos, artigos e livros estrangeiros, frente à limitada literatura nacional sobre a questão em análise.

A consequência prática do estudo foi reconhecermos que a legislação de direitos autorais não é capaz de proteger as obras originadas dos Sistemas de Inteligência Artificial, quanto estes passam a atuar de forma autônoma, quer dizer, sem a interferência humana.

\footnotetext{
${ }^{1}$ THALER. Stephen. Creativity Machine Paradigm, in Encyclopedia of Creativity, Invention, Innovation, and Entrepreneurship. ed. Elias G. Carayannis. Espringer, 2013. p. 451.
} 


\section{DOS SISTEMAS DE INTELIGÉNCIA ARTIFICIAL}

O progresso tecnológico perfez uma radical transformação no mundo social, político e econômico das diversas sociedades, não apenas pelo aumento da capacidade produtiva, mas principalmente pela geração de riquezas. EZRACHI e STUCKE $(2015)^{2}$, por exemplo, evidenciam a influência da tecnologia na competividade de mercado, inaugurando o que eles nominaram de "ambiente comercial computadorizado", em que máquinas competem entre si na precificação dos produtos oferecidos, sem influência humana.

Diversamente disto, a legislação de direitos autorais se acomodou no tempo e não foi capaz de reconhecer estas transformações sentidas pela sociedade e protagonizadas pela ciência.

Uma das mais importantes inovações levadas a efeito foi a popularização dos Sistema de Inteligência Artificial, computadores que com a assistência humana, ou as vezes até sem, são capazes, em determinados tipos de inteligência artificial, de criar obras artísticas e inovadoras.

A expressão Inteligência Artificial (IA) foi criada em $1956^{3}$, sendo uma área da ciência da computação que se especializou na capacidade de criar inteligência às máquinas, as quais devem trabalhar e reagir como os seres humanos.

"O reconhecimento de voz, a capacidade de aprendizado, o planejamento de atividade e a solução de problemas" (SINGH, 2017; SHREE, 2017) ${ }^{4}$ são algumas das atividades que os computadores devem praticar para serem incluídos na categoria de máquinas com Inteligência Artificial.

Porém, não se deve confundir Inteligência Artificial com inteligência humana, pois o ser humano, quando da prática de uma determinada conduta, não atua apenas racionalmente e objetivamente como uma máquina, mas também pelo instinto, pela intuição e por outras variáveis que influenciam na tomada de decisão. No livro "O CEREBRO RELATIVISTICO: Como ele funciona e por que ele não pode ser simulado por uma máquina

\footnotetext{
${ }^{2}$ EZRACHI, Ariel e STUCKE, Maurice E. Artificial Intelligence \& Collusion: When Computers Inhibit Competition. SSRN Electronic Journal 2017(5) · January 2015. Disponível em https://www.researchgate.net/publication/315434826_Artificial_Intelligence_Collusion_When_Computers_Inhibit_Co mpetition. Acessado em outubro de 2018.

${ }^{3}$ SKILTON, Mark e FELIX, Hovsepian. The 4th Industrial Revolution - Responding to the Impact of Artificial Intelligence on Business. Springer International Publishing. Switzerland. 2018.

${ }^{4}$ SINGH, Archana \& SHREE, Raj. Recognition of Natural Language Processing to Manage Digital Electronic Applications. International Journal of Advanced Research in Computer Science. Volume 8, n⿳ 5, May -June 2017.
} 
de turing"5, Ronald Cicurel e Miguel Nicolelis categoricamente refutam a hipótese de que uma máquina, não importa quão sofisticada, possa simulação a inteligência humana.

Em 2007 John McCarthy publicou um artigo denominado "O que é Inteligência Artificial (IA)?6", tendo respondido a esta indagação da seguinte forma:

Inteligência Artificial é quando a ciência e a engenharia se utilizam de máquinas, especialmente programas de computador, para a prática inteligente de determinados atos, sendo que inteligência é a habilidade de se alcançar um resultado (MCCARTHY, 2007).

Em termos práticos, para estes autores inteligência artificial é a capacidade do computador em predizer o futuro e, com isso, tomar decisões entre possíveis opções. Ou seja, a Inteligência Artificial toma ações baseadas no que acredita que vai acontecer (de acordo com seu raciocínio inteligente) de melhor para resolver uma tarefa ou um problema. Este "raciocínio inteligente" tem a capacidade de aprender e inovar de forma independente, proporcionando habilidades próprias para a criação de soluções originais.

\section{DA LEGISLAÇĀO AUTORAL E OS SISTEMAS DE INTELIGÉNCIA ARTIFICIAL}

Os Sistemas de Inteligência Artificial são programas de computador e, como tais, estão protegidos pela legislação autoral, mais precisamente a Lei no 9.609/98, que trata da "proteção da propriedade intelectual de programa de computador, sua comercialização no País, e dá outras providências".

Em que pese a Lei no 9.609/98 fazer referência aos chamados programas de computador, nada trata quanto a possível produtos gerados por estes programas. Assim, tomando como supedâneo o disposto na Lei 9.610/98, que "atualiza e consolida a legislação sobre direitos autorais", não estão protegidas pela legislação autoral as obras originadas dos chamados Sistemas de Inteligência Artificial, pois conforme o art. 11 da Lei no 9.610/98 só é considerado autor "a pessoa física criadora de obra literária, artística ou científica" ou até mesmo a jurídica, conforme o parágrafo único do referido artigo, mas não a máquina.

Frente a esta lacuna legal, podemos afirmar, pelo menos em um primeiro momento, que uma obra gerada por um Sistema de Inteligência Artificial não está protegida pela legislação autoral, vez que neste caso o responsável pela obra não é um autor humano.

\footnotetext{
${ }^{5}$ CICUREL, Ronald; NICOLELIS, Miguel. O CEREBRO RELATIVISTICO: Como ele funciona e por que ele não pode ser simulado por uma máquina de turing. CREATESPACE PUB. Edição: 1. Ano: 2015. País de Produção: ESTADOS UNIDOS DA AMERICA.

${ }^{6}$ MCCARTHY. John. What is Artificial Intelligence?. 2007. Disponível em: <http://wwwformal.stanford.edu/jmc/whatisai.pdf>. Acesso em: julho de 2018.
} 
Os trabalhos produzidos por Sistemas de Inteligência Artificial podem ser divididos em dois grupos distintos.

\subsection{Inteligência Artificial Como Uma Ferramenta}

Na primeira categoria podemos incluir os Sistemas de Inteligência Artificial que atuam como ferramentas de produção, neste caso o ser humano estabelece uma série de requisitos para a criação da obra, oferecendo ainda os insumos necessários para o desenvolvimento do projeto, o Sistema atuaria apenas na confecção do trabalho préestabelecido.

Neste caso, o verdadeiro autor da obra é o ser humano, pois a máquina, mais precisamente o Sistema de Inteligência Artificial, atuaria apenas como um instrumento para o alcance do bem pretendido pelo autor intelectual.

Necessário consignar que o ser humano não atua apenas com a apresentação da ideia, mas se socorre de toda uma série ações para gerar o produto, tal como acontece com o ato de se tirar uma fotografia, em que a máquina é apenas um instrumento para que o autor humano possa captar uma determinada imagem. Calha consignar, ademais, que a obras fotográficas estão protegidas pela Lei de Direitos Autorais, conforme art. $7^{\circ}$, inc. VII da Lei 9.610/98.

\subsection{Inteligência Artificial Como Criador Autônomo}

Na segunda categoria estão os Sistemas de Inteligência que atuam independente da vontade humana, neste caso, por consequência da engenhosidade matemática que envolve a tomada de decisões destes Sistemas, o trabalho é aleatório e não précondicionado ao agir humano.

Neste caso, os trabalhos produzidos pelos Sistemas de Inteligência Artificial não estão protegidos pela legislação autoral, pois são produzidos por uma máquina ou por um processo mecânico que opera aleatoriamente ou autonomamente sem qualquer intervenção ou atuação criativa de um autor humano.

Neste contexto, caso uma obra seja autonomamente criada por um Sistema de Inteligência Artificial, esta cairá no domínio público, pois conforme o art. 10 da Lei 9.610/98 a atuação humana não foi determinante para a concepção do trabalho. 


\title{
DA NECESSIDADE DE ADEQUAÇÁO DA LEGISLAÇÁO AUTORAL
}

Pela atual legislação autoral, conforme o que se encontra retro descrito, investir em programas sofisticados que atuam com uma proporção cada vez menor de atuação humana, resultando em um constante aumento do poder criativo, é economicamente inviável, frente a ausência de proteção legal quanto aos trabalhos alcançados e a possibilidade de a obra cair no domínio público.

Igual problemática foi constatada na legislação dos Estados Unidos da América. Em 2017 Shlomit Yanisky-Ravid e Xiaoqiong (Jackie) Liu?, no artigo "When Artificial Intelligence Systems Produce Inventions: The 3A Era and an Alternative Model for Patent Law", expuseram a lacuna existente na lei de patentes americana, que não prevê a possibilidade de registro de patentes por não humanos:

\begin{abstract}
A lei não considera a possibilidade de um inventor não humano. Precedentes em questões relacionadas à propriedade intelectual, abordando as leis de direitos autorais, não considerados não-humanos, como máquinas e animais, como criadores dentro da lei de direitos autorais (YANISKY-RAVID e LUI, 2017, pg. 18, tradução nossa).
\end{abstract}

Assim, ver-se que é necessário modificarmos a legislação autoral a fim de protegermos as obras geradas de forma autônoma pelos Sistemas de Inteligência Artificial, sob pena de reconhecermos como inócuo o incentivo à criação, o uso e a melhoria da Inteligência Artificial.

Alguns autores defendem que a modificação da legislação autoral para proteger o que seja produzido de forma autônoma pelo Sistema de Inteligência Artificial passa pela necessidade de ampliação do que seja "autor", devendo nesta expressão serem incluídos humanos e não humanos ${ }^{8}$.

Para outros, como YANISKY-RAVID e LUI (2017), o alargamento do conceito de autor não resolve o problema. Estes autores defendem que a proteção dada pela lei de direitos autorais é limitada e não impede que outros criem sistemas similares.

Data maxima venia, comungamos do entendimento de que esta ampliação não é o melhor caminho para a solução do problema legal, devendo a saída ser alcançada pelo que se encontra descrito no descrito no art. 88 da Lei no 9.279/96, vejamos a norma:

\footnotetext{
${ }^{7}$ YANISKY-RAVID, Shlomit and LIU, Xiaoqiong (Jackie), When Artificial Intelligence Systems Produce Inventions: The 3A Era and an Alternative Model for Patent Law (March 1, 2017). Cardozo Law Review, Forthcoming. Available at SSRN: https://ssrn.com/abstract=2931828 or http://dx.doi.org/10.2139/ssrn.2931828.

${ }^{8}$ Colin R. Davies and Ryan Abbot have (independently) both argued that computers should be considered legal authors/inventors under relevant IP law. See Ryan Abbott, I Think, Therefore I Invent: Creative Computers and the Future of Patent Law, 57 B.C. L. REV. 1079 (2016); Colin R. Davis, An Evolutionary Step in Intellectual Property Rights - Artificial Intelligence and Intellectual Property, 27 COMPUTER L. \& SECURITY REV. 601 (2011).
} 
Art. 88 A invenção e o modelo de utilidade pertencem exclusivamente ao empregador quando decorrerem de contrato de trabalho cuja execução ocorra no Brasil e que tenha por objeto a pesquisa ou a atividade inventiva, ou resulte esta da natureza dos serviços para os quais foi o empregado contratado.

Com base na referida norma, é necessário que a Lei 9.610/98 passe a considerar como autor do trabalho gerado autonomamente por Sistema de Inteligência Artificial o contratante do serviço ou o desenvolvedor do programa, vez que a máquina atuará sob o comando de um destes ou até de ambos. A alteração diretamente na legislação é a forma mais eficiente de resolução do problema destacado neste artigo, uma vez que, em geral, a jurisprudência possui uma visão pobre e cada vez mais ultrapassada sobre o assunto, portanto, não estarão bem posicionados para enfrentar os novos desafios que continuam a representar (CALO, 2016) ${ }^{9}$.

A legislação autoral do Reino Unido coaduna com a referida interpretação, ao declinar que as obras geradas por Programas de Inteligência Artificial são atribuídas a pessoa que tomou as providências necessárias para a criação da obra ${ }^{10}$.

A partir do momento em que a Lei de Direitos Autorais passar a entender que a Inteligência Artificial é o resultado de um serviço prestado ao contratante do trabalho ou ao desenvolvedor do programa, será possível afirmar que aquilo que for produzido autonomamente ou não por estes sistemas passará a estar protegido patrimonialmente e moralmente pelo ordenamento jurídico.

A passagem da autoria do produto da máquina para o desenvolvedor ou para a empresa resolve em definitivo a problemática das obras geradas autonomamente por Sistemas de inteligência Artificial caírem no domínio público.

\section{NECESSIDADE DE RECONHECER QUE A OBRA E FRUTO DO SISTEMA DE INTELIGÊNCIA ARTIFICIAL}

Como restou descrito, no caso de uma obra literária, dramática, musical ou artística ser gerada de forma autônoma por um Sistema de Inteligência Artificial, defendemos a necessidade de a Lei n 9.610/98 considerar autor o desenvolvedor do programa ou o contratante do serviço.

\footnotetext{
${ }^{9}$ CALO, Ryan, Robots in American Law (February 24, 2016). University of Washington School of Law Research Paper No. 2016-04. Available at SSRN: https://ssrn.com/abstract=2737598. Acessando em outubro de 2018.

${ }^{10}$ Copyright, Designs and Patents Act, 1988, c. 48, § 9(3) (U.K.). - In the case of a literary, dramatic, musical or artistic work which is computer-generated, the author shall be taken to be the person by whom the arrangements necessary for the creation of the work are undertaken.
} 
Com esta reestruturação não apenas se incentivaria o uso do Sistema de Inteligência Artificial, sem uma longa e controversa revisão das normas, como se permite que as empresas passarem a investir, com segurança, grande capital na criação de máquinas de inteligência artificial ou mesmo contratar os produtos gerados por estas máquinas, pois estariam protegidas pela lei de direitos autorais.

Garantir os direitos autorais da pessoa que tornou possível a operação da Inteligência Artificial parece ser a abordagem mais sensata, mas não podemos nos esquecer que é necessário que haja identificação do trabalho gerado pelo Sistema de Inteligência.

Levada a efeito esta modificação normativa incentivaríamos não apenas esta forma de produção, como também impediríamos a omissão na divulgação dos Sistemas de Inteligência Artificial no processo produtivo, vez que permitir que uma obra produzida por um Sistema de Inteligência Artificial seja registrada em nome do contratante do trabalho, em nada se confunde com a necessidade de se publicizar a quem se deveu a faísca criativa que envolveu a produção da obra, mais precisamente a máquina.

Reconhecer o Sistema de Inteligência Artificial no processo produtivo protege e incentiva não apenas quem contrata o Sistema, mas também o próprio Sistema e o desenvolvedor do programa.

Deixar de reconhecer que a obra é decorrente do trabalho desenvolvido por um Sistema de Inteligência Artificial poderia gerar diversos danos, patrimoniais ou não, inclusive impossibilitar que o contratante do serviço possa reivindicar os direitos autorais decorrentes da obra.

\section{CONSIDERAÇOES FINAIS}

O desenvolvimento dos Sistemas de Inteligência Artificial abriu a necessidade de rediscutirmos o processo criativo e consequentemente a legislação autoral que regulamenta a matéria.

A atual falta de interlocução entre a legislação e a realidade gera um dano incomensurável para a produção artística e científica, pois não reconhecer um produto como sido gerado autonomamente por um Sistema de Inteligência Artificial faz com que a obra caia no domínio público.

Esta situação não apenas limita o processo de produção de Sistemas de Inteligência Artificial, como prejudica aqueles que pretendem investir no referido Sistema. 
Neste sentido, modificar a legislação autoral considerando como autor das obras geradas de forma autônoma por um Sistema de Inteligência Artificial o desenvolvedor do programa ou o contratante do serviço é uma questão de sobrevivência do Sistema de Inteligência Artificial e do processo criativo decorrente deste modelo.

Deve ser destacado, ainda, que além de defendermos a necessidade de modificação do conceito de autor, reclamamos a necessidade de ser reconhecido o Sistema de Inteligência Artificial no processo produtivo, com o fito de incentivar não apenas aquele que contrata o Sistema, como também o próprio Sistema e o desenvolvedor do programa.

A manutenção da falha legislativa pode resultar em uma diminuição de novos trabalhos oriundos dos Sistemas de Inteligência Artificial, valiosos para estudiosos, pesquisadores e consumidores, alcançando, ainda, um atraso significativo no progresso tecnológico e artístico da sociedade moderna.

Pela atual legislação, investir em programas sofisticados que atuam com uma proporção cada vez menor de atuação humana, resultando em um constante aumento do poder criativo, é economicamente inviável, frente à ausência de proteção legal quanto aos resultados.

É necessário adequarmos a legislação autoral à nova realidade tecnológica com o fim de protegermos as obras geradas de forma autônoma pelos Sistemas de Inteligência Artificial, sob pena de reconhecermos como inócuo o incentivo à criação, o uso e a melhoria da Inteligência Artificial.

\section{REFERENCIAS}

BRASIL. Constituição (1988). Constituição da República Federativa do Brasil: 1988. Brasília, DF: Câmara dos Deputados;

Lei no 9.279 de 14 de maio de 1996. Regula direitos e obrigações relativos à propriedade industrial. Diário Oficial da República Federativa do Brasil, Poder Executivo, Brasília, DF, DOU de 15 de maio de 1996.

Lei no 9.609 de 19 de fevereiro de 1998. Dispõe sobre a proteção da propriedade intelectual de programa de computador, sua comercialização no País, e dá outras providências. Diário Oficial da República Federativa do Brasil, Poder Executivo, Brasília, DF, DOU de 20 de fevereiro de 1998 e retificado no DOU de 25 de fevereiro de 1998.

Lei $\mathrm{n}^{0} 9.610$ de 19 de fevereiro de 1998. Altera, atualiza e consolida a legislação sobre direitos autorais e dá outras providências. - Lei de Direitos Autorais. Diário Oficial da República Federativa do Brasil, Poder Executivo, Brasília, DF, DOU de 20 de fevereiro de 1998. 
CICUREL, Ronald; NICOLELIS, Miguel. O CEREBRO RELATIVISTICO: Como ele funciona e por que ele não pode ser simulado por uma máquina de turing. CREATESPACE PUB. Edição: 1. Ano: 2015. País de Produção: ESTADOS UNIDOS DA AMERICA.

CALO, Ryan. Robots in American Law (February 24, 2016). University of Washington School of Law Research Paper No. 2016-04. Available at SSRN: https://ssrn.com/abstract=2737598. Acessando em outubro de 2018.

ERTEL, Wolfgang. Introduction to Artificial Intelligence. Translated by Nathanael Black. Second Edition. Springer International Publishing. Germany. 2017.

EZRACHI, Ariel. STUCKE, Maurice E. Artificial Intelligence \& Collusion: When Computers Inhibit Competition. SSRN Electronic Journal 2017. January 2015. Disponível em https://www.researchgate.net/publication/315434826_Artificial_Intelligence_Collusion_Wh en_Computers_Inhibit_Competition. Acessado em outubro de 2018.

GUADAMUZ, Andres. Artificial intelligence and copyright. Wipo Magazine. Disponível em: $<$ http://www.wipo.int/wipo_magazine/en/2017/05/article_0003.html\#box>. Acesso em junho de 2018.

HRISTOV, Kalin. Artificial Intelligence and the Copyright Dilemma. University of Science and Technology of China (USTC). School of Public Affairs. Vol. 57, no 03, 2017.

KHAN, Gul Muhammad. Evolution of Artificial Neural Development: In search of learning genes. Studies in Computational Intelligence no 725. Springer International Publishing. $1^{\text {a }}$ ed. 2018.

MUELLER, John Paul e MASSARON, Luca. Artificial Intelligence For Dummies. 1a ed. Wiley. 2018.

MCCARTHY, John. What is Artificial Intelligence?. 2007. Disponível em: <http://wwwformal.stanford.edu/jmc/whatisai.pdf>. Acesso em: julho de 2018.

SINGH, Archana \& SHREE, Raj. Recognition of Natural Language Processing to Manage Digital Electronic Applications. International Journal of Advanced Research in Computer Science. Volume 8, nº 5, May -June 2017.

SKILTON, Mark e FELIX, Hovsepian. The 4th Industrial Revolution - Responding to the Impact of Artificial Intelligence on Business. Springer International Publishing. Switzerland. 2018.

THALER. Stephen. Creativity Machine Paradigm, in Encyclopedia of Creativity, Invention, Innovation, and Entrepreneurship. ed. Elias G. Carayannis. Espringer, 2013. p. 451.

UNITED KINGDOM. C. 48. Copyright, Designs and Patents Act. 1998. Publicado pela primeira vez em 1988. Reimpresso Incorporando Correções 2003. Disponível em: < http://www.legislation.gov.uk/ukpga/1988/48/pdfs/ukpga_19880048_en.pdf>. Acesso em: julho de 2018.

YANISKY-RAVID, Shlomit and LIU, Xiaoqiong (Jackie), When Artificial Intelligence Systems Produce Inventions: The 3A Era and an Alternative Model for Patent Law (March 1, 2017). Cardozo Law Review, Forthcoming. Available at SSRN: https://ssrn.com/abstract=2931828 or http://dx.doi.org/10.2139/ssrn.2931828. 